\title{
CAPACITY BUILDING FOR DISASTER MANAGEMENT IN MOZAMBIQUE THROUGH TEACHING PUBLIC PARTICIPATORY GIS AND SPATIAL DATA INFRASTRUCTURE
}

\author{
V. Yordanov ${ }^{1,2, *}$, M. A. Brovelli ${ }^{1}$, D. Carrion ${ }^{1}$, L. Barazzetti ${ }^{3}$, L. J. A. Francisco ${ }^{4}$, H. R. Comia ${ }^{4,5}$, M. I. Caravela ${ }^{4}$ \\ ${ }^{1}$ Department of Civil and Environmental Engineering (DICA) \\ Politecnico di Milano, Piazza Leonardo da Vinci 32, Milan, Italy - (vasil.yordanov, maria.brovelli, daniela.carrion)@ polimi.it \\ ${ }^{2}$ Vasil Levski National Military University, Veliko Tarnovo, Bulgaria \\ ${ }^{3}$ Department of Architecture, Built Environment and Construction Engineering (DABC) \\ Politecnico di Milano, via Ponzio 31, 20133 Milan, Italy - luigi.barazzetti@ polimi.it \\ ${ }^{4}$ Lúrio University, Faculty of Natural Sciences, Bairro de Maringanha, CP 958, Pemba, Mozambique \\ - (liliett.francisco, heraclito.comia, marcelino.caravela)@unilurio.ac.mz \\ ${ }^{5}$ Lúrio University, Faculty of Engineering, Bairro Eduardo Mondlane, PO Box 958, Pemba, Mozambique
}

\section{Commission IV}

KEY WORDS: Capacity building, Disaster management, Mozambique, GIS, Spatial Data Infrastructure

\begin{abstract}
:
Mozambique is highly vulnerable to clime change induced hazards. The extreme weather impacts are directly related to the temperature and precipitation variations leading to more frequent and devastating events as floods, droughts and cyclones. Even though Mozambique has committed to international policies and has adopted mitigation measures, still it is lacking of sufficient capacity on various levels to lower the country's vulnerability level. A consortium of eight partner countries, along with Mozambique, commenced a Climate Change Induced Disaster Management in Africa (CIDMA) project which aims at building education capacity through implementing geospatial information technology for improved disaster management in Mozambique. The core of the project is in developing three 10 ECTS courses that will implement state-of-the-art techniques and methodologies for dealing with climate change induced hazards. The courses are intended from one hand to university students and staff, but on the other to local authorities, organisations and companies occupied with disaster management, and local communities. As one of course, "Public Participatory GIS and Spatial Data Infrastructure in Disaster Management" is designed to prepare students to be able to produce thematic maps through GIS and crowdsourced data, as well as various EO data. With the presented course it is expected for the students to gain valuable theoretical and practical knowledge of GIS, VGI and SDI for exploiting, managing and processing geospatial data for risk mitigation and hazard mapping. Moreover, they will be skilled in using free and open-source GIS software, desktop and mobile mapping techniques, and free web-based dissemination and processing services. In addition, it is expected for the students to develop critical judgement for analysing data with the correct tools in case of climate induced disasters. This paper describes the design, structure and topics of the "Public Participatory GIS and Spatial Data Infrastructure in Disaster Management".
\end{abstract}

\section{INTRODUCTION}

Mozambique is a developing country that is constantly facing climate induced challenges. The country is even more vulnerable to frequent climate-related hazards such as floods, droughts, wildfires and cyclones (Dyoulgerov et al., 2011; MFAN, 2018). The most devastating impacts are mainly affecting the population and their livelihood, which is predominantly agriculture. Mozambique is ranked 154 out of 181 according to the 2018 NDGain with high vulnerability to climate change impacts and low readiness (Chen et al., 2015). With such a variety of problems Mozambique is in a crucial need to increase the number of highly educated specialists in the area of disaster management. Such topics are treated in a few academic courses at bachelor level at Mozambican universities, mainly introducing the fundamental theory and not focusing on the practical implementation. Thus, building capacity in higher education can be considered as an immense priority.

For the previously mentioned reasons a consortium of eight partnering institutions from Sweden, Portugal, Italy and Mozambique was founded, initiating the Climate Change Induced Disaster Management in Africa (CIDMA) project with the main objective of building education capacity to improve disaster management in Mozambique, using geospatial information technology. The project has been selected by Erasmus+ Programme of the European Commission and it is dedicated to universities and university staff, higher education students, local authorities, organisations and companies occupied with disaster management, and local communities that are considered the most vulnerable group. The most fundamental specific objective is the development of three up to date 10 ECTS courses, namely "Disaster Risk and Climate Change", "Spatial Modelling for Disaster Analysis", and "Public Participatory GIS and Spatial Data Infrastructure in Disaster Management".

As one of the courses, the "Public Participatory GIS and Spatial Data Infrastructure in Disaster Management" module will be developed in a cooperation between Politecnico di Milano and Lúrio University. The course will introduce Volunteering Geographic Information (VGI) and Spatial Data Infrastructures (SDI) through an integrated approach for implementing theoretical and practical classes.

The overall aim of the course is to prepare the students with the knowledge and skills needed to produce disaster maps through state-of-the-art GIS and remote sensing techniques including the invaluable contribution of public participation for data gathering, through remote or in-situ collaborative mapping. Practical experience with data provided by services dedicated to climate

\footnotetext{
* Corresponding author
} 
induced disaster monitoring and management will be shown and discussed. The course will introduce valuable knowledge in the field of GIS, geospatial data management and mapping, which can be very helpful and needed by decision makers and stakeholders for implementing the right mitigation measures and strategies.

\section{CIDMA PROJECT}

The consortium of eight partnering institutions from Sweden, Portugal, Italy and Mozambique and seventeen associated partners in Mozambique was created and proposed the Climate Change Induced Disaster Management in Africa (CIDMA) project with the main objective of building education capacity to improve disaster management in Mozambique, using geospatial information technology. The consortium aims at increase the knowledge on the use of spatial data and modelling, in order to foresee and prepare for climate induced hazard risks. The project has been selected by Erasmus+ Programme of the European Commission under the action Capacity Building in the field of Higher Education 2019 (Call Reference EAC/A03/2018), it started in 2019 and will continue till 2022. The partnering countries are represented mainly by higher educational institutions: Sweden - Lund University (as Primary Investigator) and Royal Institute of Technology; Portugal - Universidade de Lisboa; Italy - Politecnico di Milano and Mozambique - Eduardo Mondlane University, Lúrio University, Zambezi University and the Academy of Sciences of Mozambique (ASM). The seventeen associated partners in Mozambique are represented by different social, educational and environmental ministries, as well as other key administrative and research institutions.

More specifically, CIDMA project has four target groups and seven specific objectives. The objectives of the project are previsioned for universities and university personnel, higher education students, local authorities, organisations and companies occupied with disaster management, and lastly the local communities that are considered the most vulnerable group. The specific objectives are focused on several tracks. The primary and most fundamental one is the development of three up-to-date 10 ECTS courses in disaster management - "Disaster Risk and Climate Change", "Spatial Modelling for Disaster Analysis", and "Public Participatory GIS and Spatial Data Infrastructure in Disaster Management". The courses were chosen to fill a gap, since no relevant courses exist at the partner universities in Mozambique. The courses have been designed as complementary (see Figure 1). Moreover, they are planned for "distance" and "blended" mode allowing the students to follow the courses in a location different than the university.

After the course designed and implementation, a suitable training for the trainers at the universities and ASM will be provided, in order to be give knowledge and tools to develop and lead the designed courses. In fact, thanks to the availably of materials and after the training of trainers, the three universities in Mozambique will be able to offer the courses. The project foresees to improve the quality in education and teaching in Mozambique by implementing eLearning and Open Network Learning (ONL) tools, as well as, to improve the infrastructures at the partners with well-equipped laboratories. Another important objective is the development and implementation of a Disaster Management Tool to exploit, store and process spatial data. The last objectives are related to the dissemination of the outputs, in order to increase the awareness in the general public, local authorities and companies of the advantages and applications of spatial modelling and web-based systems; as well as strengthening the links between stakeholders and educated graduates for the purpose of mutual help.
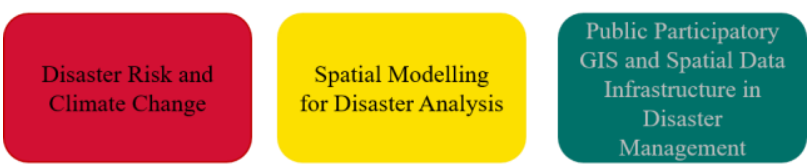

CORE WEEK

Provide students with the basic knowledge of GIS and remote sensing tools, data sources and processing techniques used in disaster risk assessment, in a climate change context

\section{KNOWLEDGE GOALS}
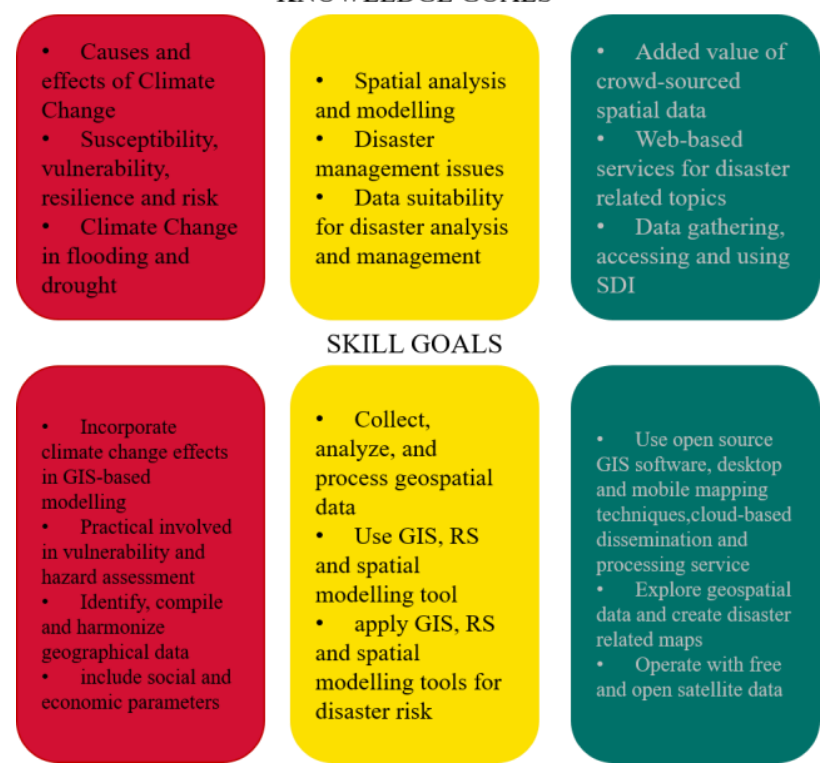

\section{SKILL GOALS}

Collect, analyze, and process geospatial data - Use GIS, RS and spatial modelling tool - apply GIS, RS and spatial modelling tools for disaster risk

Figure 1. Knowledge body of the three courses

\section{MOZAMBIQUE}

In the following section will be discussed the climate change induced hazards and issues that Mozambique is facing.

\subsection{Climate change in Mozambique}

Mozambique is one of the countries in Africa most vulnerable to natural disasters due to climate change (MICOA, 2007). Climate change manifests itself through changes in temperature and precipitation patterns, an increase in seawater levels and a frequent and intense increase in extreme weather events such as: droughts, floods, tropical cyclones in different regions of the country (MICOA, 2012), causing negative impacts on the lives and well-being of communities (Van Logchem and Queface, 2012).

Mozambique has been a signatory to the United Nations Framework Convention on Climate Change since 1995 and has adopted some actions to be developed in mitigating greenhouse gas emissions and adapting its development policies to respond to the impacts of climate change, promotion and cooperation in fields of scientific, technological, technical and socio-economic research, education, training and public information (MICOA, 2012).

\subsection{Drought}

In Mozambique, drought results from the combination of low levels of precipitation and the excessive and inappropriate use of 
soils for agriculture and livestock (MICOA, 2012). The southern and central regions of the country are the most affected by drought (FAO, 2009). Drought can cause different effects such as: loss of crops, drying of water points, reduction of primary productivity in coastal areas, reduction of grazing areas, rising prices for agricultural and staple products, rising food imports, increased calls for foreign aid, loss of human life, outbreak of disease and loss of biodiversity (MICOA, 2012). Small and large scale irrigation systems have helped to reduce the impact of regular droughts (MICOA, 2005).

\subsection{Floods}

Floods in Mozambique are caused by the precipitation that occurs in the national territory and by the runoff of water from the discharge of dams from neighbouring countries upstream from shared river basins. The country is vulnerable to floods due to 9 international river basins and several small basins. The negative impacts caused by the floods are: loss of life and property, loss of crops, outbreak of disease, displaced persons, loss of biodiversity and disruption of normal activities in different areas. The riverside areas often serve as an alternative for agricultural production of rural populations (MICOA, 2005).

\subsection{Fires}

In Mozambique $90 \%$ of forest fires are caused by humans, $5 \%$ have natural causes and another 5\% are of unknown origin. The uncontrolled fires of anthropogenic origin are due to the burning to open machambas (fields for agriculture), hunting, honey harvesting, charcoal making and to the activity of scaring away wild animals from residential areas. The northern and central regions of Mozambique are the most affected, with 4 outbreaks per $\mathrm{km}^{2}$ in a single dry season (from June to October). The impact of uncontrolled burning on the forest structure includes reducing regeneration, reducing growth, and consequently reducing the stock of forest biomass and loss of biodiversity (Sitoe et al., 2013).

\subsection{Deforestation}

Deforestation in Mozambique is more frequent in semideciduous and semi-evergreen forests where Miombo formations predominate (DINAF, 2019). The main causes of deforestation are itinerant and commercial agriculture, forestry to obtain wood and wood fuel and the expansion of housing areas (Marzoli, 2007; Saket, 1994; Sitoe et al., 2013). According to Marzoli, (2007), the annual deforestation rate in Mozambique between 1990 and 2002 was $0.58 \%$, which represents an annual conversion of 219,000 ha of forests to other types of use. The provinces with the highest average annual deforestation in the country are Nampula, Zambézia and Manica and the Provinces with the lowest average annual deforestation are Maputo, Gaza and Inhambane. To reduce deforestation reforms of the forest law, widespread conservation agriculture practices, campaigns to raise awareness of the right to land tenure through the allocation of Regularization of the Right to Use and Benefit from Land, delimitations of community lands and implementation of payment schemes for results by environmental services (DINAF, 2019), establishment of forest plantations, restoration of degraded forests and conservation of forest ecosystems, and improvements in the practice of sustainable forest management in general to reduce deforestation and forest degradation rates (MITADER, 2018).

\subsection{Landslides}

The rapid population growth has resulted in housing development in sensitive areas such as slopes and flood prone areas. The expansion of irregulated settlements can lead to issues as poor water supply network and surface water drainage systems. Which can actually be the factors for increased erosion and landslides, as well as problems associated with the use of groundwater, waste management and water pollution (Holloway and Lindsey, 1996). The most at risk regions of Mozambique are Maputo, Nampula and Zambezia. According to Manuel (2007) the landslide disaster in Mount Tumbine occurs due to several factors namely: geological settings and soil characteristics, debris flows can occur due to saturation of the existing aquifers and blocked streams. In addition, the forest disappearance had also the effect of reducing the forest cover and making land more susceptible to landslides and soil erosion, etc. (Manuel, 2007).

\subsection{Higher education and disaster management in Mozambique}

In 2009, the law on higher education was updated, whose content reinforces democratic and creative education centred on the student. And the object of study advocated is, among several, to encourage scientific, technological and cultural research and training in different areas of knowledge, technicians and scientists with high qualifications $(27 / 2009,2009)$

In terms of education system in GIS and Spatial Data Infrastructure, some higher education institutions in Mozambique offers a number of master programs mainly related to GIS. Students do, however gain experience in GIS and its application in environmental and disaster management (Pilesjö et al., 2018).

\section{PUBLIC PARTICIPATORY GIS AND SPATIAL DATA INFRASTRUCTURE}

In this paper, we focus on the "Public Participatory GIS and Spatial Data Infrastructure in Disaster Management" course, which is developed in a collaboration between Politecnico di Milano and Lúrio University. The course introduces the students to Volunteering Geographic Information (VGI) and Spatial Data Infrastructures (SDI) through an integrated approach for implementing theoretical and practical classes. In fact, the focus is on the latter where the lecture-practical hours ratio is set to be 1:2 (see Table 1) and the same weight is given to the practical outputs in the assessment method of the students' achievements.

\begin{tabular}{|c|c|}
\hline Activity & Hours \\
\hline Lectures & 25 \\
\hline Exercises & 60 \\
\hline Self-study & 105 \\
\hline Seminar & 10 \\
\hline Final Project & 50 \\
\hline Total & 250 \\
\hline
\end{tabular}

Table 1. Course hour distribution by methods of studies

The overall aim of the course is to prepare the students with the knowledge and skills needed to produce disaster maps through state-of-the-art GIS and remote sensing techniques including the invaluable contribution of public participation for data gathering, through remote or in-situ collaborative mapping. Practical experience with data provided by services dedicated to climate induced disaster monitoring and management are shown and discussed. The course is introducing valuable knowledge in the field of GIS, geospatial data management and mapping, which 
can be very helpful and needed by decision makers and stakeholders for implementing the right mitigation measures and strategies.

Globally, the trends for the usage of geospatial solutions are towards open source and it is reflecting the data collection and processing in a more accessible and profound manner (Coetzee et al., 2020) which is even more evident in the VGI (Brovelli et al., 2018a,b) . Therefore, the whole course is set to use only free and open software solutions, processing services and geospatial data.

Before enrolling for the course the students need to cover few basic prerequisites which are related to study subject modules which will provide them with basic knowledge of mathematics, statistics, geography, physical processing, environmental protection. Moreover, the students are required to have basic skills of Information Technologies.

The seven-week course is thematically divided into three blocks (Figure 2). The initial week is the "core" and it is established to be the same for the three project courses. It is dedicated to the basic theory of GIS and remote sensing, along with the practical familiarization with free and open-source software as QGIS, ESA's Sentinel Application Platform (SNAP) and cloud services as Google Earth Engine (GEE).
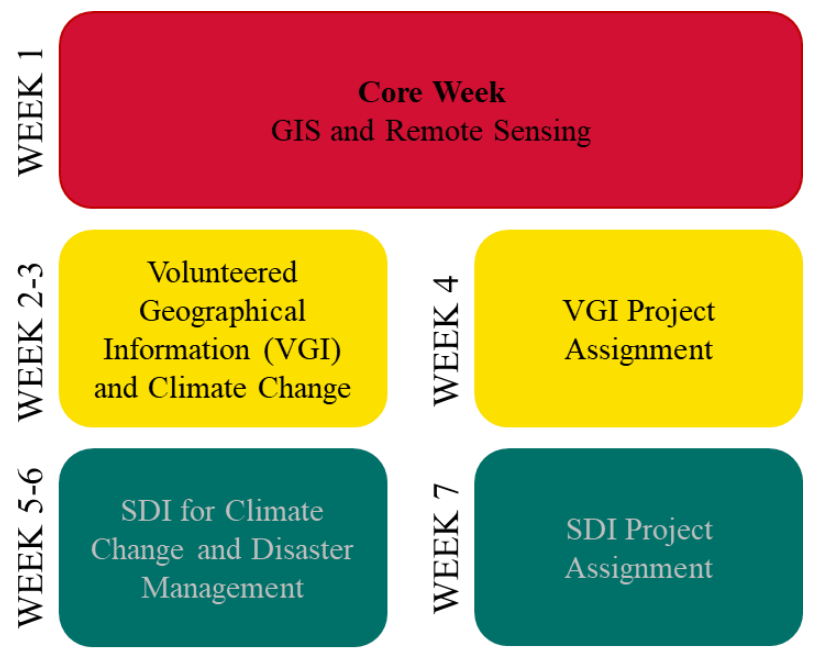

Figure 2. Weekly course structure

The second part of the course, covering three weeks, is introducing crowdsourced geospatial data through various VGI tools. The students will learn about open mapping services and their capabilities of providing a big variety of geodata applicable for disaster management. The focus is on highlighting the importance of the data quality and its use for specific applications. During the course, the students will be trained on how to organize collaborative mapping events in order to achieve predefined goals for collecting thematic geodata, not only as data users. Except the classical tools such as desktop and "field paper" mapping, mobile mapping applications for field survey and hazard-oriented applications are presented. This course block is concluding with a week dedicated to a thematic project assignment.

The last block is devoted to SDI and climate change, with a focus on disaster-related data acquisition, processing and applications. The students will have the chance to learn about hazard mapping (flood, deforestation, fire and drought) through satellite data and web services. In order to introduce web-based data management, exploitation and processing service, the block is focused on the Copernicus program, along with its platforms for Emergency
Management Service - Rapid Mapping Service, Wildfire Information System, Flood Awareness System and the Drought Observatory. Moreover and ESA's Thematic Exploitation Platforms. The practical sessions are related to hazard mapping mainly through the previously mentioned web-services, QGIS and GEE. The students will be introduced on how to develop GIS and deploy SDI through GeoNode. The block again is concluding with assigned thematic projects where the students will be able to implement the theoretical and practical knowledge obtained through the classes.

\subsection{Core week}

All three CIDMA courses are starting with mandatory "core" week lectures and practices. The main goal of this introductory week is to provide the basic knowledge body to all participating students, that would be needed to successfully comprehend any of the of the lectures or practical activities.

The activities carried out in the first week are thematically divided into covering the needed theoretical and practical knowledge related to GIS and remote sensing (Figure 3).

After each "core" part the students are required to carry out a test quiz in the form of multiple choice. In order for the student to proceed with the following weeks of course, the two quiz tests have to be passed successfully.

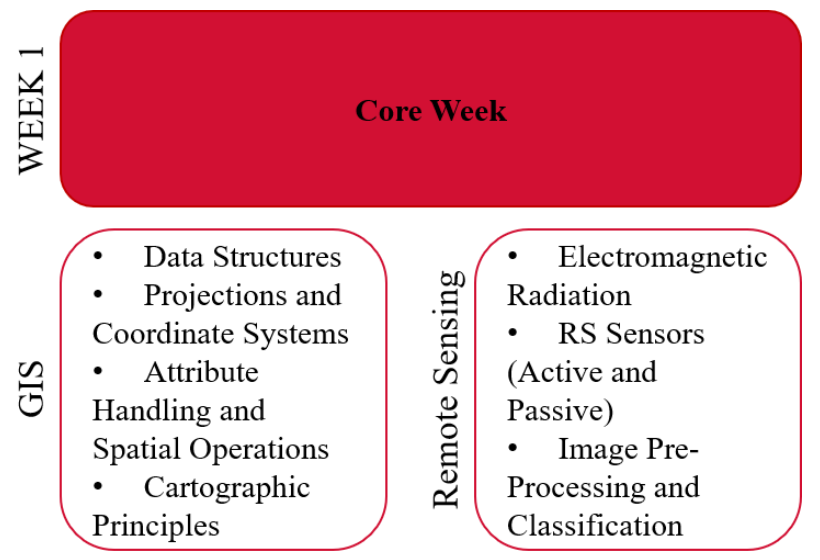

Figure 3. Core week structure and topics

4.1.1 Basics in GIS: In this part of the module the students familiarize with the fundamental theoretical and practical knowledge, as well as best practices, that allow them to become independent users. Upon completing the module, the students would are able to carry out independently spatial analyses and to produce thematic maps (e.g. Figure 4).

The studying process starts from learning how GIS data are structured and stored both in the raster and vector data model. It is highlighted the importance of projections and how do they influence the data representation. The students are going to be able to differentiate the difference between geographic and projected coordinate systems, how to proceed in cases of heterogenous data projection and even in the absence of such predefined.

Moreover, at the end of the GIS core module the students are able to search for attributes through a Structured Query Language (SQL) and perform other spatial operations, such as buffers, overlays, etc.

The related practical exercises are set to be carried out in the open-source desktop application QGIS (QGIS Development Team, 2020). 


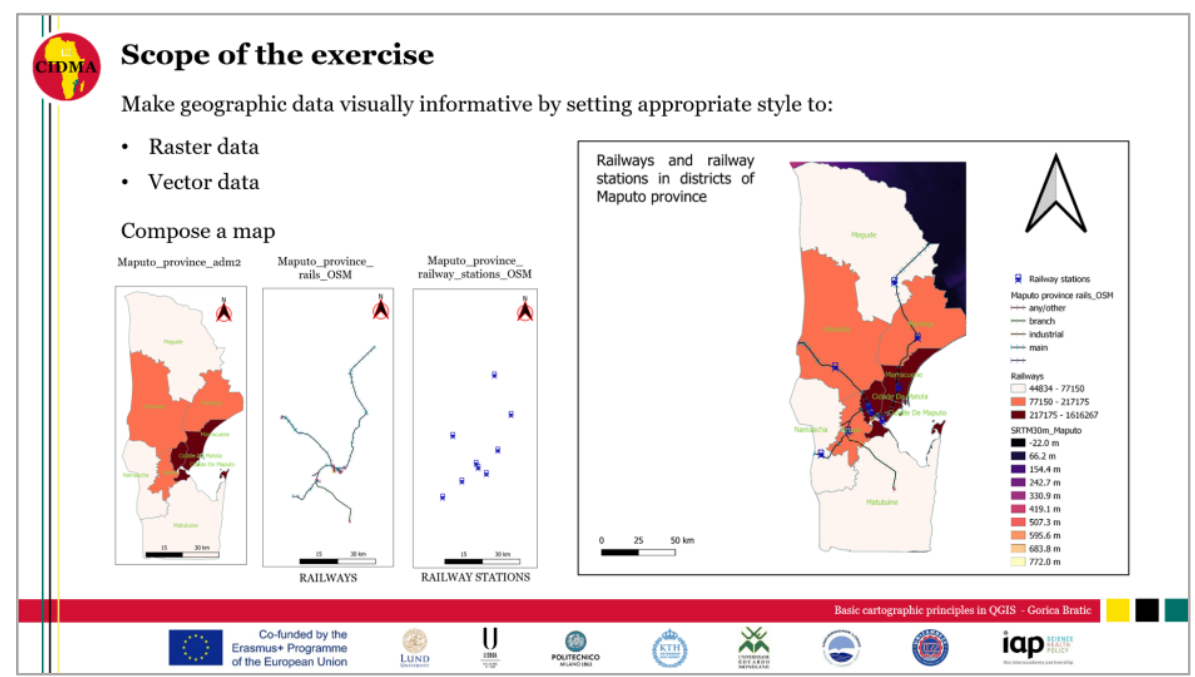

Figure 4. Example from a practical activity to compose a map

4.1.2 Basics of remote sensing: This "core" part is firstly introducing theoretically the basics of to the electromagnetic radiation, which are fundamentally needed for better comprehending any further taught remote sensing data acquisition, processing and interpretation. Topics such as different remote sensing resolutions (spatial, temporal, radiometric and spectral) are also covered in the blended theory/practice model.

Moreover, in designing the module great attention has been paid to include sufficient activities for introducing the different acquisition sensors (active and passive), , including also Light Detection and Ranging (LiDAR) and thermal imaging sensors.

At the end of the remote sensing basics the students can perform image pre-processing, enhancement, transformations and classification, through the help of other free software tools such as the Sentinel Application Platform (SNAP, 2020) and cloud processing service Google Earth Engine (Gorelick et al., 2017).

\subsection{Public Participatory GIS}

On top of the basics of GIS this module is presenting the means and web-services able to provide crowdsourced geospatial data. The students are introduced to how Volunteered Geographical Information (VGI) can contribute to climate-change related issues and hazards. Moreover, they learn how they can contribute to volunteering mapping through field surveys, mobile or desktop mapping. Except just as a geodata user, at the end of the module the students are able to evaluate the quality of crowdsourced data and also to contribute with valuable information.

Through mostly practical activities the students learn how to fully use a mapping service such as OpenStreetMap (OSM) (OpenStreetMap contributors, 2017) and to contribute to it through different OSM editors, such as iD and JOSM. The practical sessions are focused on filling missing information in Mozambique, for example missing medical amenities obtained via Humanitarian OpenStreetMap Team (HOT) Export Tool (Figure 6).

On the other hand, students are introduced to other mapping means. Such activities introduce the concept of survey using field paper (Mooney et al., 2015) where the user can print on paper sheet the area needed to be mapped and do an actual field survey marking with pen on the paper the missing amenities, which then can be digitized and uploaded to OSM. In addition, mobile tools useful for collecting geodata are introduced, such as QField,
Epicollect, Geopaparazzi and similar but hazard-related LandslideSurvey app (Pessina, 2019). The former three are general data collection mobile applications for variety of usage scenarios, while LandslideSurvey is specifically designed to map the location, type, material and other properties of already occurred mass movements (Figure 5). Moreover the app is coupled with a QGIS plug-in which allows to retrieve the recorded entries from the mobile app, then used as an input information for landslide susceptibility mapping (Yordanov and Brovelli, 2020a,b) or can be used for field surveys (Scaioni et al., 2018). Such thematic crowdsourced mobile applications had already proved their valuable role in the education process (Anbaroglu et al., 2020) and in practice (Biagi et al., 2020; Biraghi et al., 2020; Carrion et al., 2020).

Moreover, during the second week of this block (week 3) the students are introduced to collaborative mapping events, such as mapathons and mapping parties. For a mapathon, volunteers (students in the scope of the course) are invited to participate to a mapping event which is held online with a predefined area to be mapped with a straightforward aim (usually to provide disaster related data). Mapping parties are more field oriented and people are mapping together. Those events are very useful when it is needed to map amenities which would be impossible to map from satellite images. An example could be mapping the location and state (clean or blocked) of road manhole drains, which is important in case of inundations.

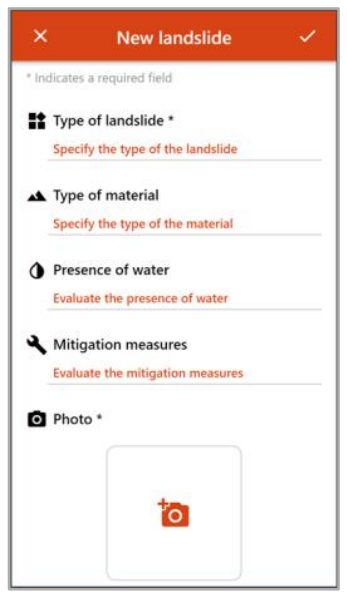

Figure 5. LandslideSurvey - Form to insert a new landslide 


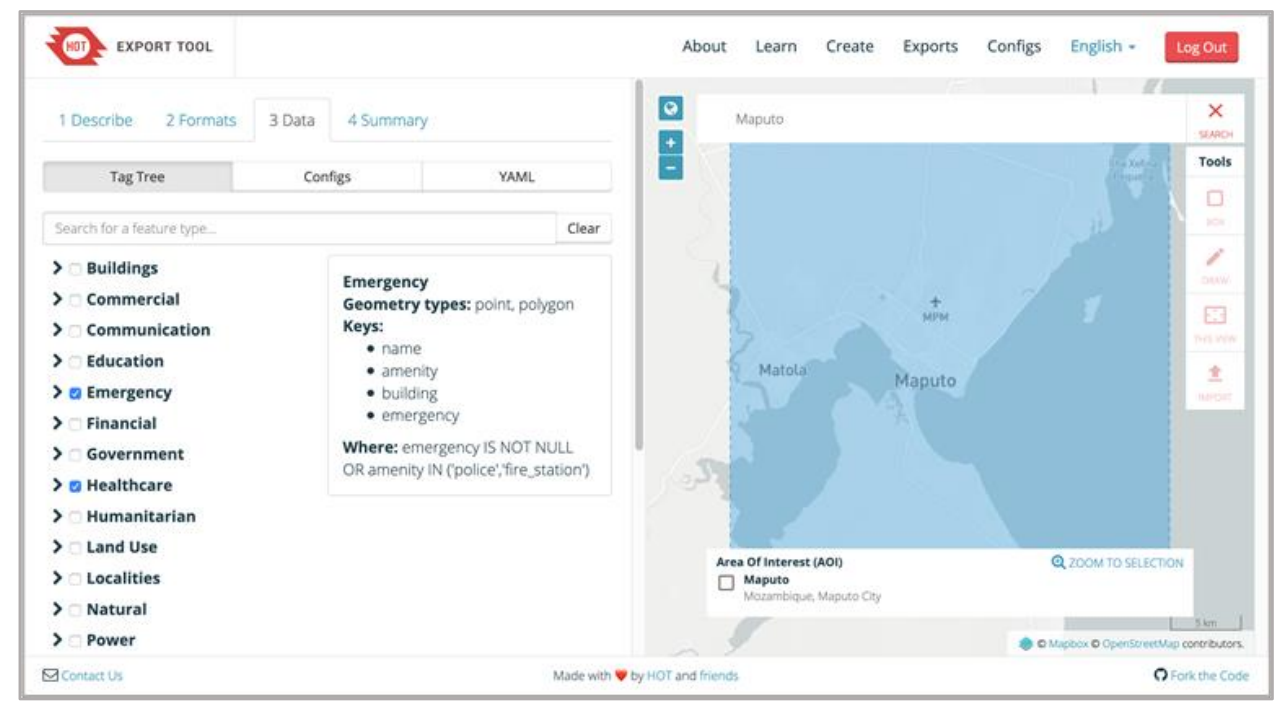

Figure 6. Example from a practical activity to obtain thematic geodata via HOT Export Tool

This second block is ending with one week of developing project assignment. The topic of the assignments is following the previous two weeks of lesson and practical activities, therefore it is focused on carrying out collaborative mapping through both field and online events.

\subsection{Spatial Data Infrastructure}

In the SDI block of the course, the students get familiar with basic concepts of SDI, starting from its components and architecture up to practical disaster-related implementations. The focus is set to be practically introduced to the different services and platforms developed under the Copernicus Programme. In fact, currently, Copernicus is the most ambitious Earth Observation programme (Jutz and Milagro-Pérez, 2017) aiming to provide to the public up-to-date, free of charge data and services useful for various thematic domains related to the protection and management of the environment.

The first one to be presented is the Copernicus Climate Change Service (C3S) which is providing high-quality datasets and processing tools (Copernicus Climate Change Service Climate
Data Store, 2020) useful for applications such as water quality monitoring, impacts assessment on biodiversity due to climate change, risk management, etc.

During the first week of the block also lecture activities to introduce to Copernicus Emergency Management Service (EMS) are planned, including topics such as Rapid Mapping service and Risk and Recovering Mapping, where the former is deriving geospatial information for particular disaster events within hours of their occurring, while the latter is more focused on the preparedness and prevention, as well as recovery.

Mozambique is highly affected by wildfires, flood events, drought and deforestation, therefore the course is dedicating lectures and practical activities to inform the students for the causes and impacts of such disasters. Moreover, it is highlighted the valuable role of earth observation data into mitigating them. Thematic Copernicus platforms - Global Wildfire Information System (GWIS); Global Flood Awareness System (GloFAS); Drought Observatory (GDO) as well as their equivalent European versions are presented. The lectures and practical activities are not considering just the direct consequences of the

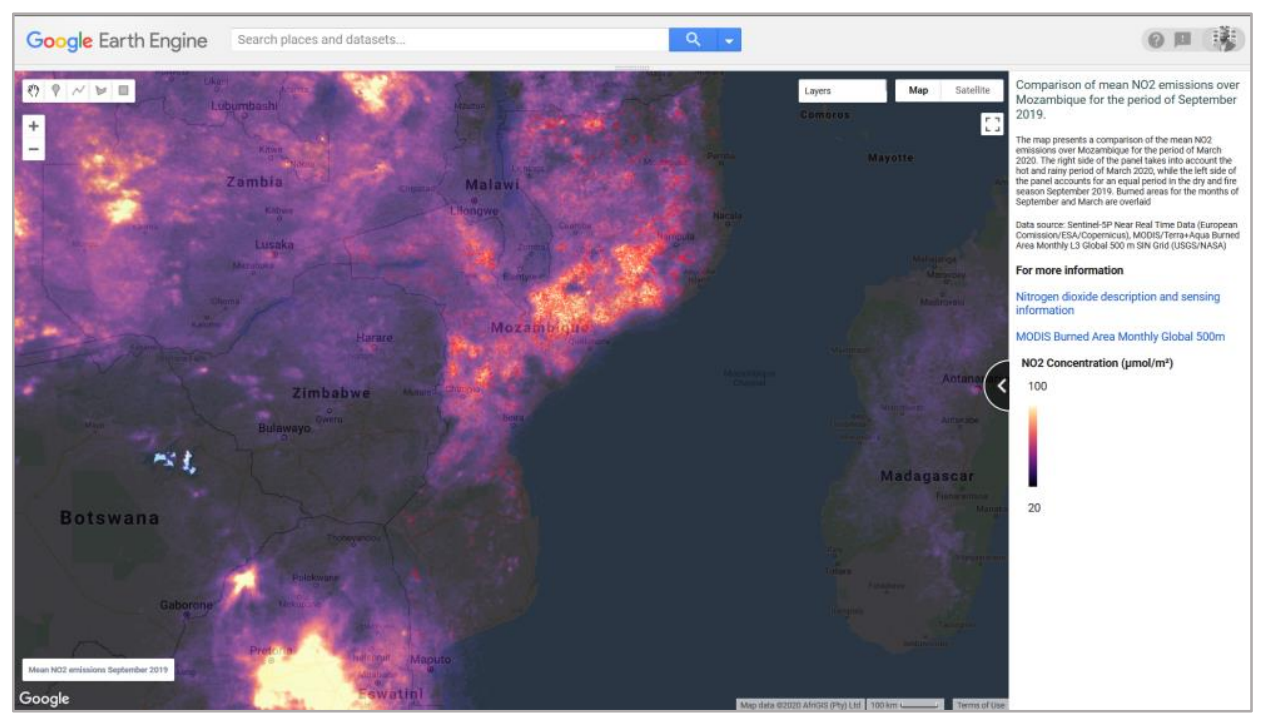

Figure 7. Example from a practical activity to monitor air quality as a result of wildfires using GEE 
disaster but also such in longer term. For example, the students will learn how to monitor air quality as a consequence of wildfires (Figure 7) through cloud processing using Google Earth Engine. The GEE will be utilized also in the scope of flood and deforestation mapping, following similar methodologies as (Canty and Nielsen, 2017) and (Brovelli et al., 2020) . It is set to investigate the consequences of the flood due to Cyclone Idai, in the area of Beira, that occurred in 2019 (Warren, 2019), by comparing the outputs from GEE and Sentinel-1 processing with products derived from Copernicus EMS Rapid Mapping.

The block concludes again with a week dedicated for project assignment, where the assignments combine the knowledge obtained from the previous two weeks and the students develop a project on disaster mapping and Google Earth Engine.

\subsection{Seminars}

Throughout the seven-week course seminar sessions, where external experts are introducing topics as "Mobile Applications for VGI", dedicated session for Mapillary, are planned. In the SDI block seminars for introducing INSPIRE, European Space Agency's (ESA) Exploitation Platforms and Data and Information Access Services (DIAS) are included.

\section{CONCLUSION}

An effective exploitation of state-of-the-art tools and up-to-date information is essential in order to face the challenges brought by climate change to the environment and human life preservation. This paper has presented one of the courses that have been developed in the framework of CIDMA (Climate Change Induced Disaster Management in Africa) Erasmus+ project to provide knowledge and tools to students in Mozambican universities. Mozambique is a developing country prone to multiple hazards, where a contribution to university programs with current knowledge about field data collection, remote sensing imagery processing and on how to take advantage of online platforms for environmental data, was required. The courses are planned to be provided in an online/blended mode to ease the students' participation.

The course that has been presented is "Public Participatory GIS and Spatial Data Infrastructure in Disaster Management". It is very much oriented to provide practical expertise. The very popular topic of Voluntary Geographic Information is discussed, introducing very well-known platforms, such as OpenStreetMap, and applications, such as Mapillary and QGIS. Also, Spatial Data Infrastructures are presented, including local and large programs, e.g. Copernicus.

The structure of the course has been discussed, in order to describe which weight has been given to the different components, and how the topics have been tackled. Most of the exercises have been prepared for country-related issues using data from Mozambique to increase the students' interest and involvement.

It is expected that the CIDMA project will foster the use of new technologies providing adequate knowledge to future technicians in order to help public administrations, organisations and companies in protecting the environment taking advantage of updated and reliable data.

\section{ACKNOWLEDGEMENTS}

The work outlined in this paper is part of project CIDMA (Climate Change Induced Disaster Management in Africa) and as such it is co-financed by the European Union in the frame of Erasmus+ programme. The project has been selected under the action "Capacity Building in the field of Higher Education 2019”, Call Reference EAC/A03/2018.

\section{REFERENCES}

27/2009, L.N., 2009. LEI No 27/2009, de 29 de setembro - Lei do ensino superior.

Anbaroglu, B., Coskun, I.B., Brovelli, M.A., Obukhov, T., Coetzee, S., 2020. Educational material development on mobile spatial data collection using open source geospatial technologies, in: International Archives of the Photogrammetry, Remote Sensing and Spatial Information Sciences - ISPRS Archives. https://doi.org/10.5194/isprs-archives-XLIII-B4-2020-221-2020

Biagi, L., Brovelli, M.A., Stucchi, L., 2020. Mapping the accessibility in openstreetmap: A comparison of different techniques, in: International Archives of the Photogrammetry, Remote Sensing and Spatial Information Sciences - ISPRS Archives. https://doi.org/10.5194/isprs-archives-XLIII-B4-2020229-2020

Biraghi, C.A., Pessina, E., Carrion, D., Brovelli, M.A., 2020. VGI Visualisation to support participatory lake monitoring: The case study of simile project, in: International Archives of the Photogrammetry, Remote Sensing and Spatial Information Sciences - ISPRS Archives. https://doi.org/10.5194/isprsarchives-XLIII-B4-2020-237-2020

Brovelli, M.A., Delipetrev, B., Zamboni, G., 2018a. Free and open source tools for volunteer geographic information and geocrowdsourcing, in: Emerging Trends in Open Source Geographic Information Systems. https://doi.org/10.4018/978-1-5225-50396.ch001

Brovelli, M.A., Minghini, M., Zamboni, G., 2018b. New Generation Platforms for Exploration of Crowdsourced GeoData, in: Earth Observation Open Science and Innovation. https://doi.org/10.1007/978-3-319-65633-5_9

Brovelli, M.A., Sun, Y., Yordanov, V., 2020. Monitoring Forest Change in the Amazon Using Multi-Temporal Remote Sensing Data and Machine Learning Classification on Google Earth Engine. ISPRS Int. J. Geo-Information. https://doi.org/10.3390/ijgi9100580

Canty, M., Nielsen, A.A., 2017. Spatio-Temporal Analysis of Change with Sentinel Imagery on the Google Earth Engine. Proc. 2017 Conf. Big Data from Sp.

Carrion, D., Pessina, E., Biraghi, C.A., Bratic, G., 2020. Crowdsourcing water quality with the simile app, in: International Archives of the Photogrammetry, Remote Sensing and Spatial Information Sciences - ISPRS Archives. https://doi.org/10.5194/isprs-archives-XLIII-B4-2020-245-2020

Chen, C., Noble, I., Hellmann, J., Coffee, J., Murillo, M., Chawla, N., 2015. University of Notre Dame global adaptation index country index technical report. ND-GAIN South Bend, IN, USA.

Coetzee, S., Ivánová, I., Mitasova, H., Brovelli, M.A., 2020. Open geospatial software and data: A review of the current state and a perspective into the future. ISPRS Int. J. Geo-Information. https://doi.org/10.3390/ijgi9020090

Copernicus Climate Change Service Climate Data Store, 2020. Copernicus Climate Change Service (C3S) (2017): ERA5: Fifth generation of ECMWF atmospheric reanalyses of the global 
climate. Ecmwf.

DINAF, 2019. Desmatamento em Moçambique (2003-2016).

Dyoulgerov, M., Bucher, A., Zermoglio, F., 2011. Vulnerability, risk reduction, and adaptation to climate change: Mozambique. Ctry. profiles. Washingt. DC World Bank Group. p.

FAO, G. de M., 2009. Quadro das Demandas e Propostas de Guiné-Bissau para o Desenvolvimento de um Programa Regional de Cooperação entre Paises da CPLP no dominio da Luta contra a Desertificação e Gestão Sustentável das Terras.

Gorelick, N., Hancher, M., Dixon, M., Ilyushchenko, S., Thau, D., Moore, R., 2017. Google Earth Engine: Planetary-scale geospatial analysis for everyone. Remote Sens. Environ. https://doi.org/10.1016/j.rse.2017.06.031

Holloway, A., Lindsey, D., 1996. PRA for risk reduction: lessons from Mozambique. Pla Notes 6-8.

Jutz, S., Milagro-Pérez, M.P., 2017. Copernicus program, in: Comprehensive Remote Sensing. https://doi.org/10.1016/B9780-12-409548-9.10317-3

Manuel, I.R. V, 2007. Reduction and management of geohazards in Mozambique. Int. J. Disaster Manag. Risk Reduct. 1, $18-23$.

Marzoli, A., 2007. Relatório do inventário florestal nacional. Direcção Nac. Terras e Florestas, Ministério da Agric. Maputo, Moçambique.

MFAN, 2018. Climate Change Profile: Mozambique.

MICOA, 2012. Estratégia Nacional de Mudanças Climáticas, 2013-2025. Maputo, Moçambique.

MICOA, 2007. Programa de Acção Nacional para a Adaptação Às Mudanças Climáticas (NAPA). Maputo, Moçambique.

MICOA, 2005. Avaliação da Vulnerabilidade as Mudanças Climáticas e Estratégias de Adaptação. Maputo, Moçambique.

MITADER, 2018. EstratégiaNacional para a Redução de Emissões de Desmatamento e Degradação Florestal, Conservação de Florestas e Aumento de Reservas de Carbono Através de Florestas (REDD+) 2016-2030.

Mooney, P., Minghini, M., Stanley-Jones, F., 2015. Observations on an OpenStreetMap mapping party organised as a social event during an open source GIS conference. Int. J. Spat. Data Infrastructures Res.

OpenStreetMap contributors, 2017. Planet dump retrieved from https://planet.osm.org .

Pessina, E., 2019. LandslideSurvey [www Document]. URL https://github.com/epessina/LandslidesSurvey

Pilesjö, P., Mansourian, A., Shindyapin, A., Alfredo Assane, A., Lenathe Muheca, E., Rwanyiziri, G., Mugisha, J., Bamutaze, Y., Nakileza, B., Maiga, G., others, 2018. Harmonizing GIS Education: South-North Perspectives: Lessons learnt from Mozambique, Rwanda, Sweden, and Uganda.

QGIS Development Team, 2020. QGIS Geographic Information System. Open Source Geospatial Foundation Project. http://qgis.osgeo.org. Qgisorg.

Saket, M., 1994. Report on the updating of the exploratory national forest inventory.

Scaioni, M., Crippa, J., Yordanov, V., Longoni, L., Ivanov, V.I., Papini, M., 2018. Some tools to support teaching photogrammetry for slope stability assessment and monitoring, in: International Archives of the Photogrammetry, Remote Sensing and Spatial Information Sciences - ISPRS Archives. https://doi.org/10.5194/isprs-archives-XLII-3-W4-453-2018

Sitoe, A.A., Guedes, B.S., Nhantumbo, I., 2013. Linha de Referência, Monitoria, Relatório e Verificação para o REDD+ em Moçambique. Relatório do pais. IIED, Londres.

SNAP ESA Sentinel Application Platform, 2020.

Van Logchem, B., Queface, A.J., 2012. Responding to climate change in Mozambique: Synthesis report. Maputo INGC, Maputo.

Warren, M., 2019. Why Cyclone Idai is one of the Southern Hemisphere's most devastating storms. Nature. https://doi.org/10.1038/d41586-019-00981-6

Yordanov, V., Brovelli, M.A., 2020a. Comparing model performance metrics for landslide susceptibility mapping, in: International Archives of the Photogrammetry, Remote Sensing and Spatial Information Sciences - ISPRS Archives. https://doi.org/10.5194/isprs-archives-XLIII-B3-2020-12772020

Yordanov, V., Brovelli, M.A., 2020b. Application of Various Strategies and Methodologies for Landslide Susceptibility Maps on a Basin-Scale: The Case Study of Val Tartano, Italy. Appl. Geomatics. https://doi.org/10.1007/s12518-020-00344-1 